\title{
Lesiones eccematosas de distribución generalizada
}

\author{
Molinero Barranco MA. ${ }^{1}$
}

Sanid. mil. 2015; 71 (4): 265-266; ISSN: 1887-8571

\section{CASO CLÍNICO}

Varón de 47 años de edad que consulta por presentar prurito intenso de la piel que desemboca en la aparición de una lesión eritematosa, de bordes vesiculosos e irregulares y superficie ligeramente escamosa en el brazo izquierdo y posteriormente aparecen lesiones semejantes en el resto del cuerpo incluyendo la cara. Unos meses antes inició tratamiento de una hepatitis C con $135 \mathrm{mg}$ de interferón alfa-2a semanalmente, administrado por vía subcutánea y ribavirina, $1.200 \mathrm{mg} /$ día por vía oral.

A la exploración presenta una placa eccematosa, pruriginosa, en el tercio inferior del brazo izquierdo. Ver figura. Se observan lesio- nes de características semejantes, de diversos tamaños que se distribuyen por los miembros inferiores y superiores, así como por el tórax, la cara y pabellones auriculares. El estado general del paciente es bueno, el hemograma y la bioquímica sanguínea son normales. Se practica una biopsia incisional del borde superior de la lesión ubicada en el brazo izquierdo. El laboratorio de anatomía patológica informa que se trata de una dermatitis psoriasiforme y espongiótica con formación de ampolla intracórnea con neutrófilos.

Se establece el diagnóstico de eccema nummular generalizado secundario a la ingesta de interferón alfa-2a y ribavirina para el tratamiento de una hepatitis C. Tras consultar con el especialista

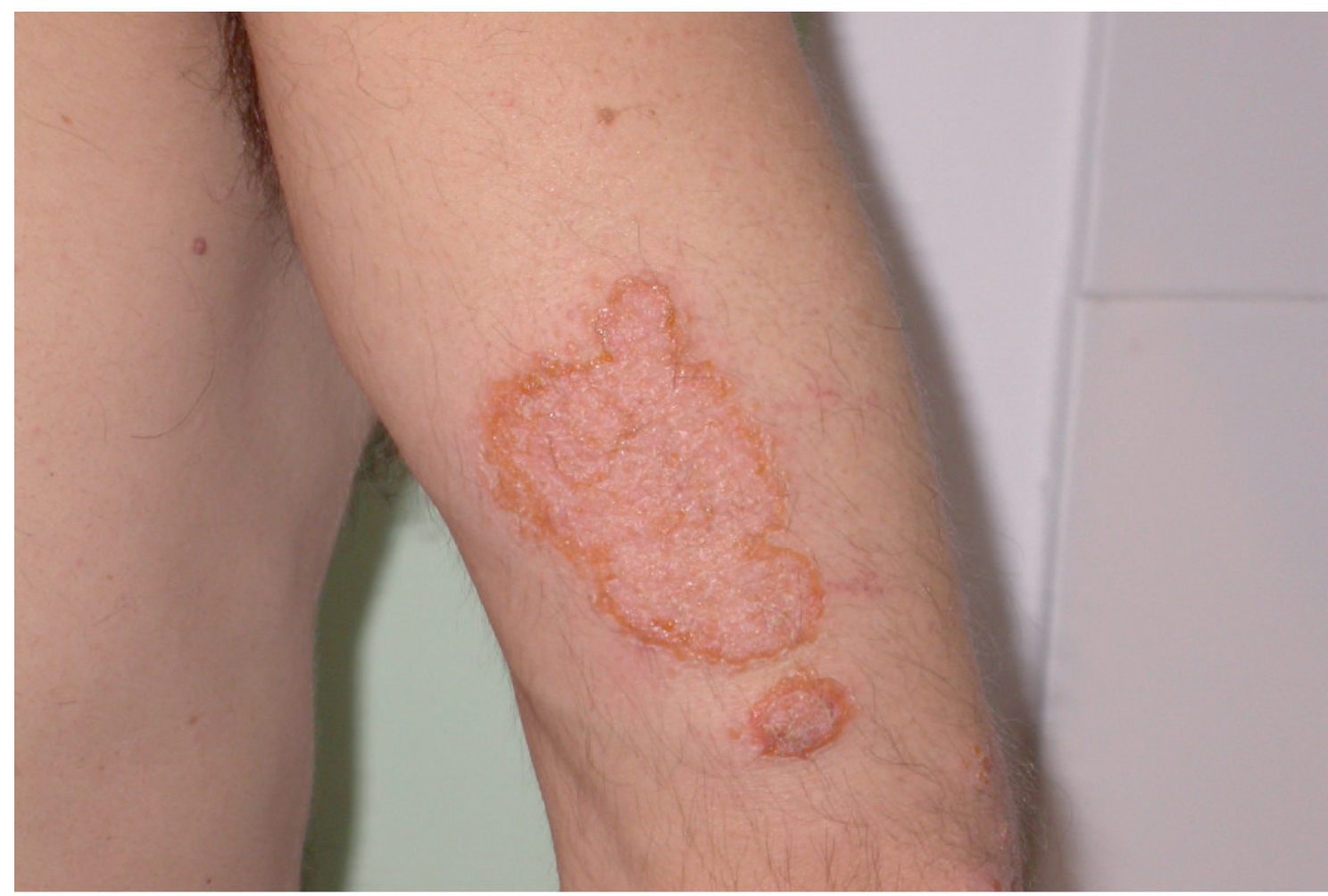

Figura 1. Lesiones eccematosas tercio inferior del brazo izquierdo.

Tcol. Médico (Retirado)

Dirección para correspondencia: mamolba@telefonica.net 


\section{Diagnóstico: Eccema nummular generalizado secundario a interferón alfa-2a y ribavirina}

de Digestivo se decide retirar el tratamiento y se inicia tratamiento con hidroxicina $25 \mathrm{mg}$ cada 8 horas y beclometasona dipropionato al $0,025 \%$ tópico cada 24 horas sobre las lesiones. El cuadro cutáneo se resuelve a los 15 días sin complicaciones.

\section{DISCUSIÓN}

Para Sookian y cols las complicaciones cutáneas son del 12$33 \%$, siendo mayor cuando se utilizan los fármacos conjuntamente que utilizando cada uno por separado. Las reacciones más frecuentes fuera del sitio de inyección son las eccematosas, alcanzando el $59 \%{ }^{1}$. Con los nuevos antivirales como el telaprevir, el rash cutáneo aparecen en el 56\% de los casos, si bien sólo el 1\%-4\% deben suspender el tratamiento por la gravedad de éste ${ }^{2}$. También se ha informado sobre la aparición del síndrome de Stevens Johnson en el $0,1 \%$ de los casos tratados con este nuevo antiviral ${ }^{2}$. Álvarez Cuesta y cols. comentan que el tratamiento de la hepatitis C puede acarrear diferentes efectos secundarios cutáneos que suelen aparecer a partir de los dos o tres meses de haber iniciado el tratamiento con interferón alfa-2a y ribavirina como la aparición de granulomas sarcoideos alrededor de cuerpos extraños en una mujer que hacía dos meses que estaba siendo tratada por padecer una hepatitis crónica $\mathrm{C}$ y que presentaba infiltradas microesferas de polimetilmetacrilato para rectificar las arrugas faciales. Aisladamente es frecuente la inflamación y el eritema en el punto de inyección. A distancia de éste se ha descrito la aparición de sarcoidosis, urticaria, fenómeno de Raynaud, alopecia y la exacerbación de dermatosis previas como la dermatitis atópica, la psoriasis o el lupus eritematoso ${ }^{3}$. La ribavirina puede producir reacciones de fotosen$\operatorname{sibilidad}^{4-6}$. Con el telaprevir es muy frecuente la aparición de anemia por lo que el control hematológico mediante un hemograma es primordial ${ }^{2}$. Parecen más frecuentes las lesiones que aparecen en la zona de inyección del interferón que las generalizadas, pero esto no se cumple en las recientes series publicadas, que incluyen un mayor número de pacientes. En nuestro caso, las lesiones se podían observar en casi todo el tegumento, como también observaron Ruiz de Casas, García-Bravo y Camacho ${ }^{7}$. Las lesiones eccematosas se caracterizan por ser lesiones eritematovesicuolas con bordes activos por donde se observa crecer la lesión, irregulares, en ara- bescos y una superficie serodescamativa secundaria a la desecación de las efímeras vesículas. El prurito es intenso. El diagnóstico diferencial se puede establecer con la psoriasis, herpes circinado, pitiriasis rosada de Gibert y dermatitis de contacto, principalmente. Aunque no existe un patrón histopatológico característico, se observa que en muchos casos predominan cuadros inespecíficos de dermatitis espongiótica, como ocurrió en el caso que nos ocupa ${ }^{8}$. Respecto al mecanismo patogénico se desconoce cómo se originan las lesiones. No obstante, se sospecha que exista una predisposición atópica subyacente ${ }^{2}$. Al retirar los medicamentos se resuelven las lesiones, si bien la aplicación tópica de un corticoide acelera la curación ${ }^{9}$. La mayoría de los casos no requieren suspensión del tratamiento y se pueden manejar sintomáticamente.

\section{BIBLIOGRAFÍA}

1. Sookoian S, Neglia V, Castano G et al. High prevalence of cutaneous reactions to interferon alfa plus ribavirin combination therapy in patients with chronic hepatitis C virus. Arch Dermatol 1999;135:1000-1.

2. Agencia Española del Medicamento. Ficha técnica de Incivo ${ }^{\circledR}$ (Telaprevir). Disponible en: http://www.aemps.gob.es/cima/fichasTecnicas.do?metodo=buscar

3. Álvarez C, Blanco S, Rodríguez E et al. Granulomas sarcoideos desarrollados alrededor de cuerpos extraños durante el tratamiento con interferon alfa y ribavirina en un pacientes con hepatitis crónica C. Actas Dermosifiliogr. 2003;94:655-9.

4. Patrk I, Morović M, Markulin A, Patrk J. Cutaneous reactions in patients with chronic hepatitis $\mathrm{C}$ treated with peginterferon and ribavirin. Dermatology 2014;228:42-6.

5. Mistry N, Shapero J, Crawford R. A review of adverse cutaneous drug reactions resulting from the use of interferon and ribavirin. Can $\mathrm{J}$ gastroenterol 2009;23:677-83.

6. Tavakoli-Tabasi S, Bagree A. A longitudinal cohort study of mucocutaneous drug eruptions during interferon and ribavirin treatment of hepatitis C. J Clin gastroenterol 2012;46:162-7

7. Ruiz de Casas A, García-Bravo B, Camacho F. Eccema generalizado a tratamiento combinado con interferón alfa- $2 \mathrm{~b}$ pegilado y ribavirina en un paciente con hepatitis crónica por virus de la hepatitis C. Actas Dermosifiliogr. 2005; 96:122-3.

8. Moore MM, Elpem DJ. Severe generalized nummular eczema secundary to interferon alfa- $2 b$ plus ribavirin combination therapy in a patient with chronic hepatitis C virus infection. Arch. Dermatol. 2004;140:215-7.

9. Vázquez-López F, Manjón-Haces JA, Pérez-Álvarez R, Pérez-Oliva N. Eczemalike lesions and disruption of therapy in patiens treated with interferon alfa and ribavirin for chronic hepatitis C: the evalue of an Interdisciplinary assesment. Br. J. Dermatol. 2004;150:1028-54. 